\title{
Effect of perinatal depression on birth and infant health outcomes: a systematic review and meta-analysis of observational studies from Africa
}

Abel Fekadu Dadi ${ }^{1,2}$, Temesgen Yihunie Akalu' ${ }^{1}$ Haileab Fekadu Wolde ${ }^{1}$ and Adhanom Gebreegziabher Baraki ${ }^{1 *}$ (D)

\begin{abstract}
Background: Antenatal depression is associated with intrauterine growth retardation, preterm birth, and low birth weight. Infants born to mothers with postnatal depression also may suffer from malnutrition and other health problems. Even though there are few single studies conducted so far, a systematic review of these studies is highly important to highlight the effect of antenatal and perinatal depression on adverse birth and infant health outcomes in Africa.
\end{abstract}

Methods: We used the Preferred Report Items for Systematic Review and Meta-analysis (PRISMA) when conducting this study. Databases like CINAHL (EBSCO), MEDLINE (via Ovid and PubMed), PsycINFO, Emcare, Psychiatry Online, and Scopus were searched. In addition, Google Scholar and references from a list of eligible studies were explored. We included good quality observational studies based on Newcastle Ottawa Scale which are published in the English language between 2007 and 2018. Heterogeneity and publication bias were assessed. Meta-analysis with a random effect model was employed to determine the pooled effect sizes with a 95\% confidence interval. The review protocol is registered in PROSPERO (CRD42018106714).

Result: We found three studies (1511 participants) and 11 studies (22,254 participants) conducted on the effect of antenatal depression on birth outcomes and perinatal depression on adverse infant health outcomes, respectively. The overall risk of having adverse birth outcomes was 2.26 (95\% Cl: 1.43, 3.58) times higher among pregnant mothers with depression. The risk of preterm birth and low birth weight was 1.77 (95\% Cl: 1.03, 3.04) and 2.98 (95\% $\mathrm{Cl}: 1.60,5.55)$ respectively. Similarly, the risk of having adverse infant health outcomes namely malnutrition and febrile illness was 1.61 (95\% Cl: 1.34, 1.95) times higher among mothers who had perinatal depression.

\footnotetext{
* Correspondence: adsh04@gmail.com

${ }^{1}$ Department of Epidemiology and Biostatistics, Institute of Public Health,

College of Medicine \& Health Sciences, University of Gondar, Gondar,

Ethiopia

Full list of author information is available at the end of the article
}

(c) The Author(s). 2022 Open Access This article is licensed under a Creative Commons Attribution 4.0 International License, which permits use, sharing, adaptation, distribution and reproduction in any medium or format, as long as you give appropriate credit to the original author(s) and the source, provide a link to the Creative Commons licence, and indicate if changes were made. The images or other third party material in this article are included in the article's Creative Commons licence, unless indicated otherwise in a credit line to the material. If material is not included in the article's Creative Commons licence and your intended use is not permitted by statutory regulation or exceeds the permitted use, you will need to obtain permission directly from the copyright holder. To view a copy of this licence, visit http://creativecommons.org/licenses/by/4.0/. The Creative Commons Public Domain Dedication waiver (http://creativecommons.org/publicdomain/zero/1.0/) applies to the data made available in this article, unless otherwise stated in a credit line to the data. 
Conclusions: We have found a significant association between antenatal depression and adverse birth outcomes, low birth weight and preterm birth. Similarly, a significant effect of perinatal depression on adverse infant health outcomes namely, malnutrition, and febrile illnesses was observed. The findings highlight that it is time to integrate mental health services with routine maternal health care services to improve birth outcomes and reduce infant morbidity.

Keywords: Antenatal depression, Perinatal depression, Adverse birth outcomes, Adverse infant health outcomes, Systematic review, Meta-analysis

\section{Background}

Depression is the third leading cause of disease burden worldwide and is predicted to become the second leading cause of the global disease burden by the year 2020 [1]. Women are twice as likely to be diagnosed with depression than men [2]. Women of child-bearing age frequently suffer from major depression [3]. Depression is also one of the most prominent mental health disorders in women following delivery [4]. Depression during pregnancy and the postnatal period, which is referred as perinatal depression onwards in this paper is a non-psychotic depressive episode that challenges both mothers and the health care providers $[5,6]$. The prevalence of depression ranges from 11.3 to $19.6 \%$ during pregnancy and $9.6 \%$ to $24.3 \%$ during the postpartum period [7-10].

Depression during pregnancy and post-partum negatively affect both maternal and fetal health $[4,11]$. According to studies from developed countries, the effect could be direct to the fetus or indirectly through unhealthy maternal behaviors arising from depression [3]. Some of the effects on the newborn are low birth weight [12-16], intra-uterine growth restriction (IUGR), preterm delivery [17], low Apgar score [18], and impaired infant growth that includes shorter length and lighter weight $[5,19]$. Similarly, based on primary studies from developed countries, postnatal depression could cause infant ill-treatment [20], alcohol abuse leading to poor infant care [21], infant irritability [22, 23], impaired cognitive function [24], malnutrition [25], and infant death [26]. However specific studies on this area are limited or lacking in low-income countries.

The mechanism by which depression causes damage to the fetus could be due to the release of stress hormones such as cortisol and catecholamine [27], which in turn affect fetal growth [19] and gestational age [28]. The other explanation could be maternal malnutrition aroused by lack of appetite [29]. Poor dietary patterns by the mother due to depression could be also another mechanism by which the effect of depression on fetal growth could be explained [18].

Even though perinatal depression is a major public health problem, most of the literature and reviews were focused on the post-delivery period and were conducted to estimate its prevalence and risk factors. Therefore, limited information is available on the effect of perinatal depression on birth and infant health outcomes in Africa. The findings from individual studies also had inconsistent findings that could result in information dilemmas and affect public health interventions. In addition, perinatal depression has become more prevalent in African countries than in any other middle- and low-income countries, and we hypothesized that its effect would be also different. The findings from such specific settings will make policymakers and programmers more reactive as it clearly shows the problem in the context of Africa. Moreover, Africa is least developed continent with underdeveloped health infrastructure; therefore, pooling the effect of perinatal depression in Africa with that of developed countries would underestimate the problem.

\section{Method}

\section{Searching strategy and inclusion criteria}

We followed the Preferred Report Items for Systematic Review and Meta-analysis (PRISMA) when conducting this study [30]. We have done a thorough systematic search of the literature in CINAHL (EBSCO), MEDLINE (via Ovid and PubMed), PsycINFO, Emcare, Psychiatry Online, Scopus databases, and using search engines such as Google, Google Scholar, and following snowball search strategy (Additional file 1).

Our first review question was "Is there an association between antenatal depression and adverse birth outcomes such as low birth weight and preterm birth? The second review question was "Does perinatal depression (depression during pregnancy and postpartum) have an association with adverse infant health outcomes such as malnutrition and illnesses?"

Observational studies conducted in Africa from 2007 to 2018, which were written in English-language, used standardized tools for screening depression, and measured infant health outcomes following the standardized guideline for Integrated Management of New-born and Childhood Illness (IMNCI) were included. We included studies published after 2007 for information is dynamic and considering the most updated pieces of evidence would make the review result more homogeneous, upto-date, and help us to have a recent image of the problem in Africa. 


\section{Outcome definitions}

Primary studies that used the following definition of outcome were considered. Low birth weight, birth weight less than 2500 g; Preterm birth, birth occurring after 20 complete weeks and before 37 complete weeks of gestation. Malnutrition was also considered when the Middle-Upper Arm-Circumference (MUAC) of the infant is less than $110 \mathrm{~mm}$ for infants 6-12 months and a weight-for-length $\geq-2$ Z-scores of the WHO Child Growth Standards median for infants under six months old.

Studies conducted among specific risk populations, such as HIV/AIDS patients, patients with chronic illnesses, and migrant populations were excluded. Following systematic searching, eligible studies were exported to Endnote version 7, and duplicates were removed. Studies that fulfilled the inclusion criteria through their title and abstract review were considered for full-text review. The full text of the included studies was reviewed by two reviewers (AFD, AGB). Disagreements were resolved by discussion and/or with the assistance of the third reviewer (HFW).

\section{Quality assessment and data extraction}

The quality of evidence and the risk of bias were assessed by AFD and AGB using the Newcastle-Ottawa Scale (NOS) [31]. Based on the NOS, we had three classifications of studies: Good quality, studies with $\geq 7$ points; Fair quality, studies with $2-6$ points; Poor quality, studies with less than or equal to one [32]. All studies fulfilled the criterion for good quality and were included in the final review and meta-analysis. Structured data abstraction form was prepared and the following information was collected from each primary study: Name of the author, year of publication, country, country income, study setting, study design, sample size, time by which depression screening conducted, the tool used to screen depression, and effect sizes OR/RR/HR with 95\% confidence intervals (Table - 1).

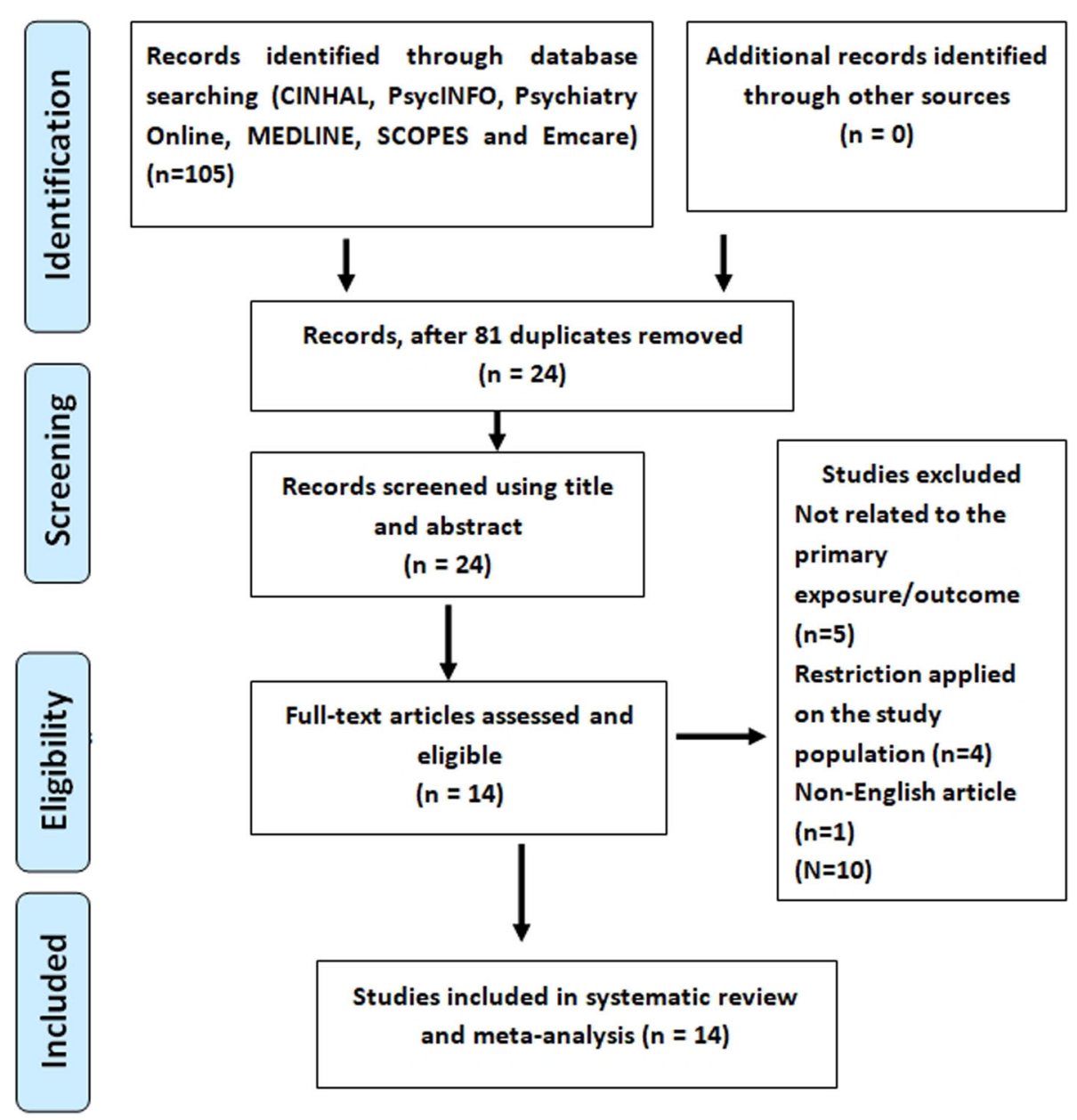

Fig. 1 PRISMA flow chart showing study selection for systematic review and meta-analysis of the effect ofperinatal depression on birth and infant health outcomes in Africa, 2007 - 2018 


\section{Data analysis}

Data synthesis was conducted independently for each primary outcome. Publication bias was checked using the Funnel plot and Egger's test [33] and Duval and Tweedie's Trim and Fill analysis was conducted to correct any identified publication bias [34]. The percentage of Heterogeneity among studies was checked by $I^{2}$ statistics, and $\mathrm{I}^{2}$ which is greater than $50 \%$ was considered as substantial [35]. We used the random effect model to deal with the heterogeneity detected in this review [36]. A meta-analysis of odds ratios and relative risks for adverse birth and infant health outcomes were conducted following a log transformation of the effect sizes. STATA version 14 software was used for data analysis [37]. The protocol was registered in PROSPERO with the registration number CRD42018106714.

\section{Result}

\section{Study screening process}

We identified a total of 105 research articles, among which 37 studies were related to the effect of antenatal depression on birth outcomes, and 68 were

Table 1 Summary of studies conducted on the effect of postnatal depression on birth and infant health outcome

\begin{tabular}{|c|c|c|c|c|c|c|c|c|c|c|c|}
\hline No & Author, Year & $\begin{array}{l}\text { Country, } \\
\text { income }\end{array}$ & $\begin{array}{l}\text { Study } \\
\text { setting }\end{array}$ & $\begin{array}{l}\text { Study } \\
\text { design }\end{array}$ & $\begin{array}{l}\text { Sample } \\
\text { size }\end{array}$ & $\begin{array}{l}\text { Time follow up } \\
\text { started }\end{array}$ & $\begin{array}{l}\text { Tool } \\
\text { used }\end{array}$ & $\begin{array}{l}\text { Type of } \\
\text { outcome }\end{array}$ & $\begin{array}{l}\mathrm{RR} / \\
\mathrm{OR}\end{array}$ & $\mathrm{LCl}$ & $\mathrm{UCl}$ \\
\hline \multicolumn{12}{|c|}{ Included studies on effect of antenatal depression on adverse birth outcomes } \\
\hline$[1]$ & Bindt C et al. 2013 & Middle, Ghana & $\mathrm{HI}$ & Longitudinal & 719 & $3 r d$ & $\begin{array}{l}\text { PHQ- } \\
9 \geq 10\end{array}$ & PTB & 2.1 & 0.8 & 5.6 \\
\hline [2] & $\begin{array}{l}\text { Wado WD et al. } \\
2014\end{array}$ & Low, Ethiopia & Community & Longitudinal & 537 & $2 n d \& 3 r d$ & $\begin{array}{l}\mathrm{EPDS} \geq \\
13\end{array}$ & LBW & 1.77 & 1.03 & 3.04 \\
\hline [3] & $\begin{array}{l}\text { Mochache K et al. } \\
2018\end{array}$ & Kenya, Middle & $\mathrm{HI}$ & Longitudinal & 255 & All & $\begin{array}{l}\mathrm{EPDS} \geq \\
13\end{array}$ & PTB & 3.8 & 2.1 & 4.6 \\
\hline \multicolumn{12}{|c|}{ Included studies on effect of perinatal depression on adverse infant health outcomes } \\
\hline \multirow[t]{2}{*}{ [4] } & $\begin{array}{l}\text { Adewuya AO et al. } \\
2008\end{array}$ & Nigeria, Middle & $\mathrm{HI}$ & case control & 242 & 6 to 12 weeks & DSM-III-R & Poor weight & 3.41 & 1.3 & 8.52 \\
\hline & & & & & & & & Poor height & 3.28 & 1.03 & 10.47 \\
\hline \multirow[t]{3}{*}[5]{} & $\begin{array}{l}\text { Ndokera R et al. } \\
20,011\end{array}$ & Zambia, Middle & Community & $\begin{array}{l}\text { Cross } \\
\text { sectional }\end{array}$ & 278 & 2 to 12 months & $\begin{array}{l}\text { SRQ- } \\
20 \geq 8\end{array}$ & Serious illness & 1.64 & 0.51 & 5.24 \\
\hline & & & & & & & & Diarrhea & 1.32 & 0.71 & 2.48 \\
\hline & & & & & & & & Underweight & 1.48 & 0.35 & 6.22 \\
\hline$[6]$ & Guo N et al. 2013 & Ghana, Middle & $\mathrm{HI}$ & Follow up & 654 & $3 r d$ & $\mathrm{PHQ} \geq 10$ & $\begin{array}{l}\text { Febrile } \\
\text { illnesses }\end{array}$ & 1.32 & 1.01 & 1.74 \\
\hline$[7]$ & Guo N et al. 2013 & $\begin{array}{l}\text { Cote devour, } \\
\text { Middle }\end{array}$ & $\mathrm{HI}$ & Follow up & 654 & $3 r d$ & $\begin{array}{l}\mathrm{PHQ}>= \\
10\end{array}$ & $\begin{array}{l}\text { Febrile } \\
\text { illnesses }\end{array}$ & 1.57 & 1.2 & 2.07 \\
\hline$[8]$ & $\begin{array}{l}\text { Ashaba Set al } \\
2015\end{array}$ & Uganda, Low & $\mathrm{HI}$ & case control & 166 & 1 to five yrs & (M.I.N.I.) & Malnutrition & 2.4 & 1.11 & 5.18 \\
\hline \multirow[t]{4}{*}[9]{} & $\begin{array}{l}\text { Weobong B et al. } \\
2015\end{array}$ & Ghana, Middle & Community & longitudinal & 16,560 & 4 to 12 weeks & $\begin{array}{l}\mathrm{PHQ}- \\
9 \geq 10\end{array}$ & Diarrhea & 1.8 & 1.45 & 2.14 \\
\hline & & & & & & & & cough & 1.49 & 1.28 & 1.7 \\
\hline & & & & & & & & Fever & 1.8 & 1.49 & 2.11 \\
\hline & & & & & & & & Vomiting & 1.98 & 1.26 & 2.71 \\
\hline \multirow[t]{2}{*}[10]{} & $\begin{array}{l}\text { Madeghe BA et al. } \\
2016\end{array}$ & Kenya, Middle & $\mathrm{HI}$ & $\begin{array}{l}\text { cross } \\
\text { sectional }\end{array}$ & 200 & 6 to 14 weeks & $\begin{array}{l}\mathrm{EPDS} \geq \\
13\end{array}$ & Non-EB & 6.14 & 2.45 & 13.36 \\
\hline & & & & & & & & Under weight & 4.4 & 1.91 & 11.93 \\
\hline$[11]$ & $\begin{array}{l}\text { Wemakor A et al. } \\
2016\end{array}$ & Ghana, Middle & $\mathrm{HI}$ & $\begin{array}{l}\text { cross } \\
\text { sectional }\end{array}$ & 384 & 0-59 months & $\begin{array}{l}\text { CED- } \\
S \geq 16\end{array}$ & Stunting & 2.48 & 1.29 & 4.77 \\
\hline \multirow[t]{2}{*}[12]{} & \multirow{2}{*}{$\begin{array}{l}\text { Benett IM et al. } \\
2015\end{array}$} & \multirow[t]{2}{*}{ Ethiopia, Low } & \multirow[t]{2}{*}{ Community } & \multirow[t]{2}{*}{ longitudinal } & \multirow[t]{2}{*}{1885} & \multirow[t]{2}{*}{13 months } & \multirow[t]{2}{*}{ CED $>9$} & Stunting & 0.91 & 0.81 & 1.02 \\
\hline & & & & & & & & underweight & 1.01 & 0.89 & 1.15 \\
\hline [13] & $\begin{array}{l}\text { Neamah H et al. } \\
2018\end{array}$ & Tanzania & Community & Follow up & 1031 & 18-36 months & $\begin{array}{l}\mathrm{PHQ}- \\
9 \geq 9\end{array}$ & Stunting & 1.07 & 0.73 & 1.56 \\
\hline [14] & $\begin{array}{l}\text { Wemakor A et al. } \\
2018\end{array}$ & Ghana, Middle & Community & $\begin{array}{l}\text { Cross } \\
\text { sectional }\end{array}$ & 200 & 6-23 months & $\begin{array}{l}\text { CES- } \\
D \geq 20\end{array}$ & Stunting & 1.05 & 0.58 & 1.91 \\
\hline
\end{tabular}


related to the effect of perinatal depression on infant health outcomes. Following screening 81 duplicates were removed, and from the other 24, ten studies were excluded due to unrelated exposure/outcome (5 studies), restriction on the study population (4 studies), and non-English language use (1 study). Finally, a total of 14 studies: Three for the effect of antenatal depression on birth and 11 studies for perinatal depression effect on infant health were included in the systematic review and meta-analysis (Fig. 1).

\section{Study characteristics}

From the three studies we used to determine the effect of antenatal depression on birth outcomes, we had a total sample size of 1511 . These studies were conducted in Ethiopia [38], Kenya, and Ghana [39]. All were longitudinal in study design. The study conducted in Ethiopia was community-based whereas the other two were institution-based studies. The study conducted in Ghana used the Patient Health Questionnaire (PHQ-9) to screen depression whereas the studies from Ethiopia and Kenya used the Edinburgh Postnatal Depression Scale (EPDS).

Among the 11 studies used to determine the effect of perinatal depression on infant health outcomes, we found a total sample size of 22,254. Four studies were from Ghana [40-43] and the other seven studies were from Ethiopia, Kenya [44], Uganda [45], Tanzania [46], Nigeria

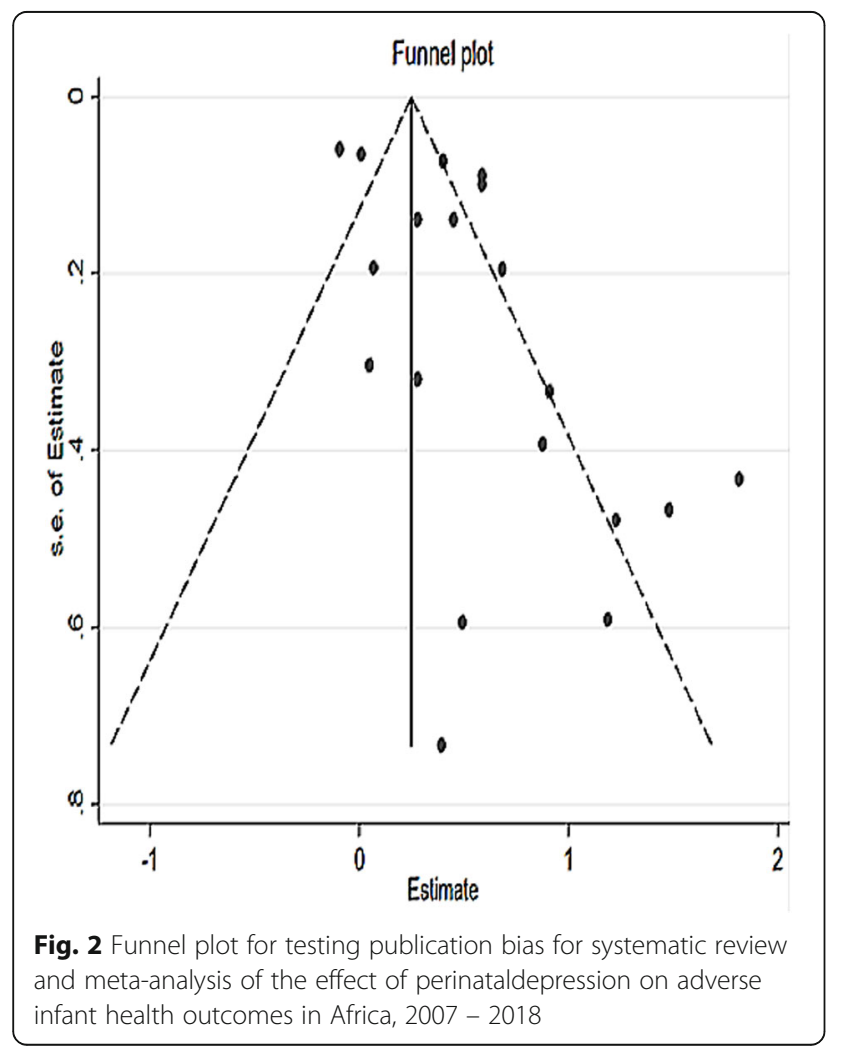

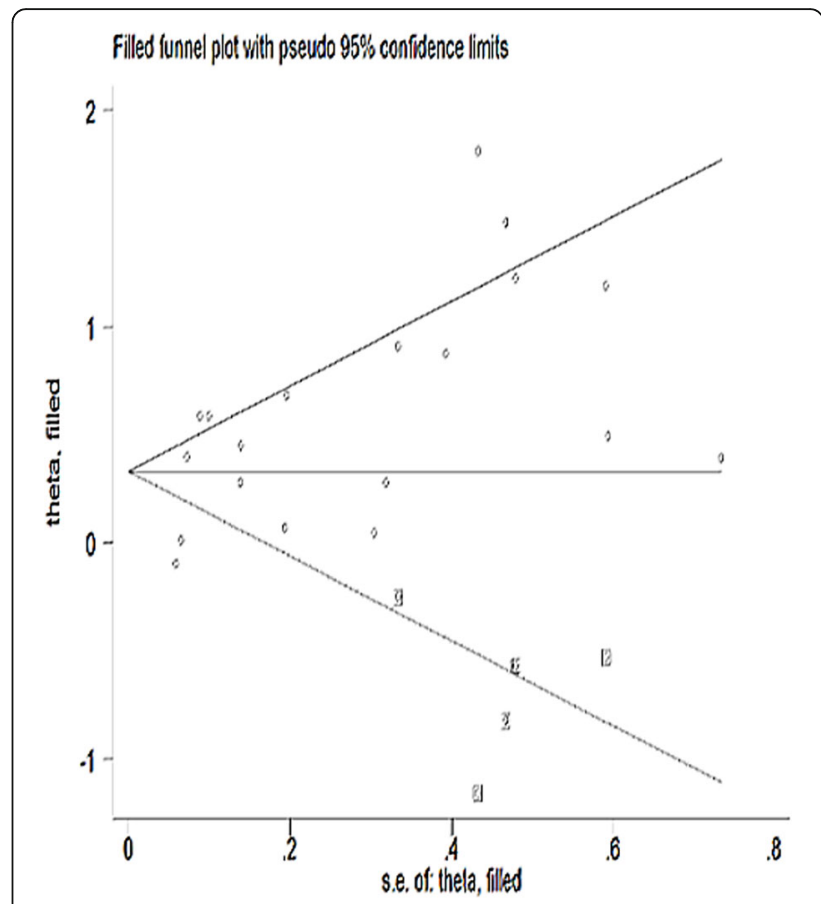

Fig. 3 Funnel plot after trim and fill analysis in the systematic review and meta-analysis of the effect of perinataldepression on adverse infant health outcomes in Africa, 2007 - 2018

[47], Zambia [48], and Cote d'Ivoire [40]. Regarding the study setting, six studies were health institution-based and five were community-based. The screening tools used were Diagnostic and Standard Manual for mental Disorder-Revised (DSM-III-R), Self-Reporting Questionnaire (SRQ-20), Patient Health Questionnaire (PHQ), Mini International Neuropsychiatric Interview (M.I.N.I), EPDS, and Center for Epidemiological Studies Depression (CES-D) (Table 1).

The presence of publication bias was detected by the asymmetrical distribution of studies on the funnel plot (Fig. 2) and a significant egger's test $(P$-value $<0.05)$. Therefore, the Duval and Tweedie's Trim and Fill analysis was used to produce the final pooled estimates (Fig. 3). The presence of any influential study was checked by sensitivity analysis and no study with significant influence on the pooled estimate was observed (Fig. 4).

\section{Effect of antenatal depression on birth outcomes}

In this review, we had two studies that showed association between antenatal depression and preterm birth (PTB) with RR of 2.1 and 3.8. The pooled estimate in the random effect model has also shown a similar direction of association between antenatal depression and PTB with a pooled Relative Risk of 2.98 (95\% CI: 1.60, 5.55). We had only one eligible study that determined the relationship between antenatal depression and low birth weight that estimated a 


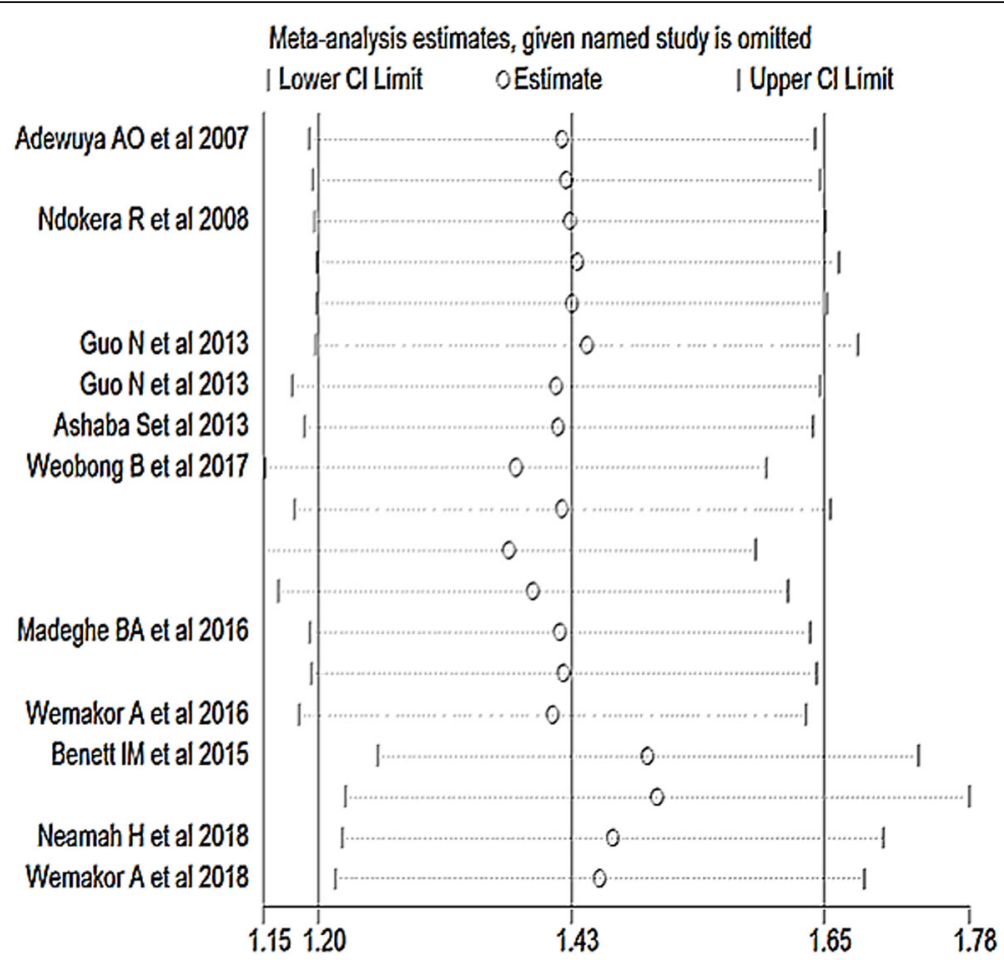

Fig. 4 Sensitivity analysis of studies included in the systematic review and meta-analysis of the effect ofperinatal depression on infant health outcomes in Africa, 2007 - 2018

relative risk of 1.77 (95\%CI: 1.03, 3.04). When these three studies are pooled, we found a relative risk of 2.26 (95\% CI: 1.43, 3.58), which means a risk of having adverse birth outcomes was 2.26 times higher among mothers who had antenatal depression symptoms than their counterparts (Fig. 5).

Effect of postnatal depression on infant health outcomes We conducted a meta-analysis of 11 studies that determined the risk of malnutrition among children born to mothers who had perinatal depression. Among these studies, five found no significant association and six studies showed a positive relationship. The RR in the primary studies ranged from 0.91 to 6.14 . Pooling these studies gave a relative risk of 1.65 (95\% CI: 1.24, 2.19), which means the risk of being malnourished was 1.65 times higher among mothers with a history of perinatal depression than children born to a mother with no mental depression.

A total of eight studies addressed the association between infant illnesses with mother's perinatal depression exposure; two of them found no significant association but the other studies showed a significant effect of postnatal depression on the occurrence of infant illnesses. The relative risk of the studies ranged from 1.32 to 1.98 . The pooled estimate of the association between perinatal depression and infant illnesses was 1.62 (95\% CI 1.48, 1.77); meaning the risk of the infant developing illness was 1.62 times higher among mothers who had depression than their counterparts. The pooled estimates from the two adverse infant health outcomes, malnutrition, and infant illness, showed a relative risk of 1.61 (95\% CI: 1.34, 1.95) meaning, the overall risk of having adverse infant health outcomes was 1.61 times higher among mothers with perinatal depression symptoms than mothers without perinatal depression (Fig. 6).

Most importantly, the effect of perinatal depression on the risk of adverse infant health outcomes was consistent across studies using screening tools and diagnostic criteria for identifying mothers with depression symptoms. Similarly, the effect of perinatal depression on adverse infant health outcomes was consistent irrespective of study sample size, study design, time of measurement, and estimation techniques used in the primary studies (Table 2).

\section{Discussion}

Depression in pregnancy and the postnatal period in many African countries is not well documented and has not been given attention for intervention due to competing priorities and the belief that it does not 


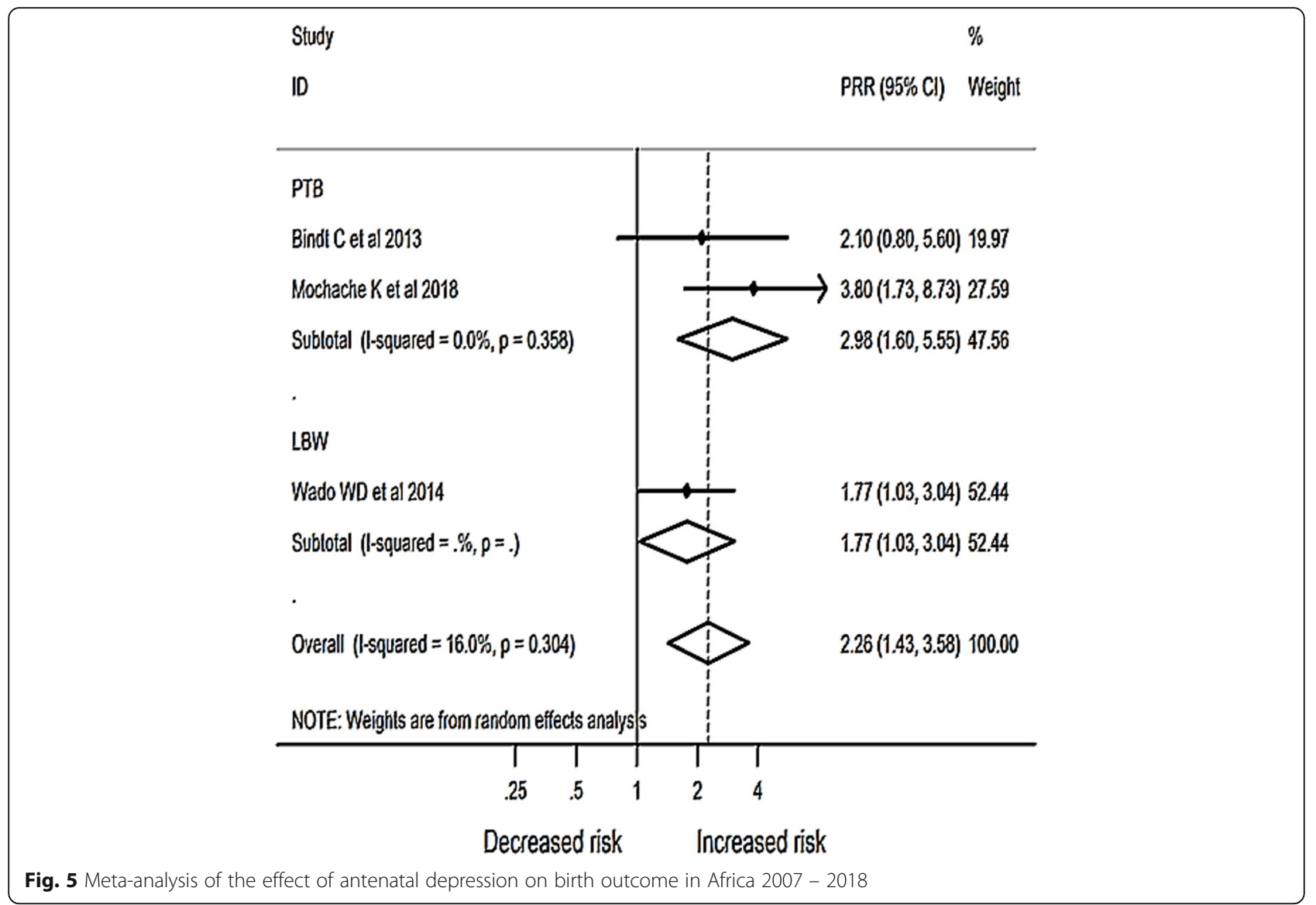

immediately cause fatalities. However, its effect is devastating as it affects household income, productivity, child development [49], and quality of life [50]. This review assessed the effect of perinatal depression on birth and infant health outcomes in Africa. The study found that there is a clear relationship between perinatal depression and adverse birth and infant health outcomes that is LBW, PTB, malnutrition, and infant illnesses.

Women with antenatal depression were more likely to have infants with low birth weight. This finding is consistent with previous reviews $[13,17,51,52]$. The risk of preterm birth was also found to be higher among women with antenatal depression than their counterparts. This association was also supported by other systematic reviews and meta-analyses [53, 54]. The possible reason for these associations could be both biological and/or nutritional. Biologically, the release of stress hormones such as cortisol and catecholamine's during pregnancy [27] affect fetal growth [19] and gestational age [28]. Nutritionally, depressed pregnant mothers are more likely to have appetite disturbance that could affect their nutritional uptake through which fetal growth can be impaired [29].
Postnatal depression was also found to negatively affect the nutritional status of infants and this finding was in line with previous systematic reviews $[55,56]$. This could be due to poor infant feeding practices of mothers who have depression [44], including decreased breastfeeding duration [57], efficacy, and increased breastfeeding difficulty [58]. On the contrary, a review by Surkan and his colleagues reported a lack of association between postnatal depression and infants being underweight [59].

Similar to previous reviews [55,60], mothers' exposure to postnatal depression predicted a higher likelihood of infant illnesses. This could be because poorly fed infants tend to be immune-suppressed and are more likely to suffer from infections [53]. Depression has been shown to impact maternal caretaking behavior, which includes bottle feeding and other malpractices that make the infants be exposed to infectious agents [61]. One study reported that a mother who was depressed during midpregnancy would have a $30 \%$ risk of being unresponsive toward her new baby [62].

The effect of postnatal depression on the adverse infant health outcomes in this study was consistent across studies using screening tools and diagnostic criteria for identifying mothers with depression 


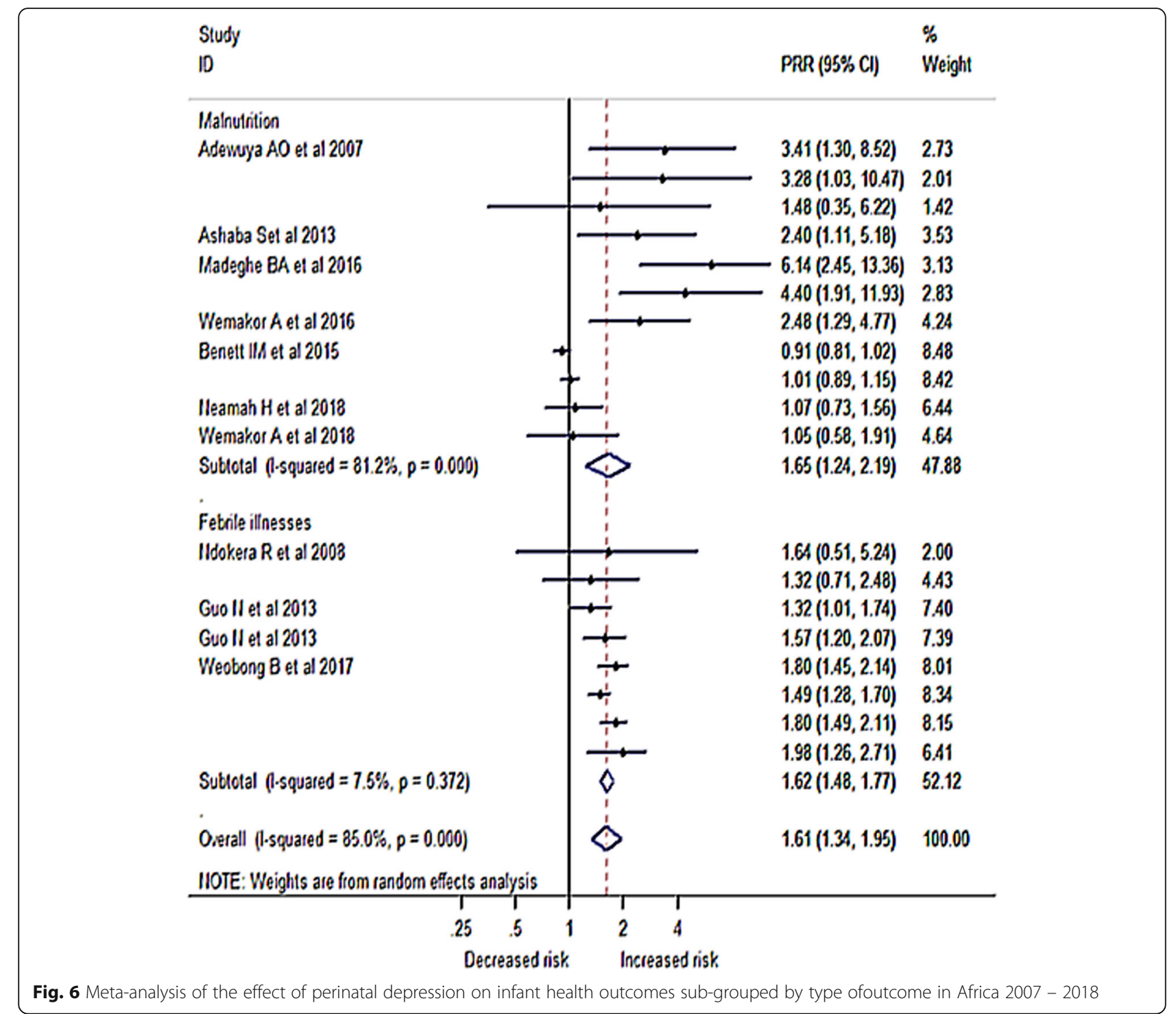

symptoms. Similarly, the effect of perinatal depression on adverse infant health outcomes was also consistent irrespective of a study sample size, study design, time of measurement, and estimation techniques used in the primary studies.

Since the consequences of perinatal depression are deleterious for both the mother and the baby, prevention of its occurrence should be strengthened. Otherwise, using nonpharmacologic treatments like cognitive-behavioral therapy, supportive psychotherapy, conjoint therapy with the partner should come first to avoid both explicit and implicit side-effects of pharmacologic interventions [63]. However, if the former two approaches are not effective, pharmacologic interventions should be considered.

This review is comprehensive and based on our extensive search it is the first of its kind in Africa. In addition, in our sub-analysis, we have controlled all possible factors that may affect our estimation of the pooled effect sizes. The inclusion of studies published only in the English language and those which measured depression using screening tools with different versions and cut-off values are the limitations of this review. However, we believed that the findings from this review are important and could be used as a highlight to consider perinatal depression as a major public health problem, and thinking the how to address the disorder should be a key message.

\section{Conclusions}

This systematic review and meta-analysis was conducted to determine the effect of perinatal depression on birth outcomes and infant health in Africa. We 
Table 2 Sub-group analysis of the effect of postnatal depression on infant health outcomes in Africa from 2007 to 2018

\begin{tabular}{|c|c|c|c|}
\hline Variable for sub-analysis & Number of studies & Sample size (N) & PRR, 95\%Cl, Higgins test \\
\hline \multicolumn{4}{|l|}{ Time of depression measurement } \\
\hline The first one to six months & 5 & 18,310 & $1.82(1.54,2.15), P^{2}=63.2 \%$ \\
\hline The first one to five years & 6 & 3944 & $1.13(0.94,1.35), P^{2}=52.5 \%$ \\
\hline \multicolumn{4}{|l|}{ Study design } \\
\hline Longitudinal & 5 & 20,784 & $1.38(1.12,1.69), P^{2}=85.2 \%$ \\
\hline Cross sectional & 6 & 1470 & $2.32(1.58,3.40), P^{2}=50.5 \%$ \\
\hline \multicolumn{4}{|l|}{ Sample size } \\
\hline$<=384$ & 6 & 1470 & $2.32(1.49,3.60), P^{2}=55.7 \%$ \\
\hline$>384$ & 5 & 20,784 & $1.42(1.16,1.74), P^{2}=89.9 \%$ \\
\hline \multicolumn{4}{|l|}{ Type of screening tool used } \\
\hline Diagnostic tool & 3 & 16,968 & $1.75(1.54,2.00), P^{2}=31.7 \%$ \\
\hline Screening tool & 8 & 5286 & $1.40(1.13,1.75), I^{2}=78.5 \%$ \\
\hline \multicolumn{4}{|l|}{ Estimation method } \\
\hline Odds ratio & 5 & 1192 & $2.77(1.72,4.46), I^{2}=58.8 \%$ \\
\hline Relative risk & 4 & 19,754 & $1.37(1.09,1.72), P^{2}=89.1 \%$ \\
\hline Hazard ratio & 2 & 1308 & $1.44(1.19,1.74), P^{2}=0.0 \%$ \\
\hline
\end{tabular}

PRR Pooled Risk Ratio

found a significant association between perinatal depression and adverse birth and infant health outcomes. More importantly, this association was consistent among studies that used a screening tool and diagnostic criteria to identify mothers with depression symptoms. Our findings highlight that it is time to integrate mental health services with other routine maternal health services to improve birth outcomes and reduce infant morbidity.

\section{Abbreviations}

CES-D 20: Center for Epidemiologic Studies depression scale 20;

$\mathrm{Cl}$ : Confidence Interval; DSM-III-R: Diagnostic and Statistical Manual of mental disorders version III; EPDS: Edinburgh Postnatal Depression Scale; HIV: Human immunodeficiency Virus; LBW: Low Birth Weight; MINI: Mini International Neuropsychiatric Interview; NOS: Newcastle-Ottawa Scale; OR: Odds Ratio; PHQ-9: Patient Health Questionnaire-9; PRISMA: Preferred Report Items for Systematic review and meta-analysis; PRR: Pooled Relative Risk; PTB: Preterm Birth; RR: Relative Risk; SRQ-20: Self-Reporting Questionnaire

\section{Supplementary Information}

The online version contains supplementary material available at https://doi. org/10.1186/s13690-022-00792-8.

Additional file 1. Example of our search strategy in Pubmed.

\section{Acknowledgments}

We would like to thank Angie Willcocks from the University of South Australia for her expert advice and proofreading of this review.

\section{Authors' contributions}

AFD, AGB, TYA, and HFW have actively participated during conception and design, data extraction, or analysis and interpretation of data. All authors read and approved the final version of the manuscript.

\section{Funding}

None.

Availability of data and materials

All the data by which the results are based are available in the manuscript.

\section{Declarations}

Ethics approval and consent to participate

Not applicable.

\section{Consent for publication}

Not applicable.

\section{Competing interests}

All authors declare that there is no competing interest.

\section{Author details}

${ }^{1}$ Department of Epidemiology and Biostatistics, Institute of Public Health, College of Medicine \& Health Sciences, University of Gondar, Gondar, Ethiopia. ${ }^{2}$ School of Public Health, College of Medicine and Public Health, Flinders University, Bedford Park, Australia.

Received: 22 February 2021 Accepted: 7 January 2022

Published online: 20 January 2022

\section{References}

1. Federal Democratic Republic of Ethiopia Ministry of Health. National Mental Health Strategy 2012/13-2015/16. Addis Ababa: Federal Democratic Republic of Ethiopia Ministry of Health; 2012.

2. Girgus JS, Yang K. Gender and depression. Current Opinion in Psychology. 2015:4:53-60.

3. Bonari L, Pinto N, Ahn E, Einarson A, Steiner M, Koren G. Perinatal risks of untreated depression during pregnancy. Can J Psychiatr. 2004;49(11):726-35. https://doi.org/10.1177/070674370404901103.

4. Chi X, Zhang P, Wu H, Wang J. Screening for postpartum depression and associated factors among women in China: A cross-sectional study. Front Psychol. 2016;7:1668.

5. Gelaye B, Rondon M, Araya R, Williams MA. Epidemiology of maternal depression, risk factors, and child outcomes in low-income and middle- 
income countries. Lancet Psychiatry. 2016;3(10):973-82. https://doi.org/10.1 016/S2215-0366(16)30284-X.

6. Evans J, Heron J, Francomb H, Oke S, Golding J. Cohort study of depressed mood during pregnancy and after childbirth. BMJ. 2001;323(7307):257-60. https://doi.org/10.1136/bmj.323.7307.257.

7. Banti S, Mauri M, Oppo A, Borri C, Rambelli C, Ramacciotti D, et al. From the third month of pregnancy to 1 year postpartum. Prevalence, incidence, recurrence, and new onset of depression. Results from the perinatal depression-research \& screening unit study. Compr Psychiatry. 2011;52(4): 343-51. https://doi.org/10.1016/j.comppsych.2010.08.003.

8. Lobato G, Moraes CL, Dias AS, Reichenheim ME. Postpartum depression according to time frames and sub-groups: a survey in primary health care settings in Rio de Janeiro. Brazil Arch Womens Ment Health. 2011;14(3):18793. https://doi.org/10.1007/s00737-011-0206-6.

9. Faisal-Cury A, Menezes P. Prevalence of anxiety and depression during pregnancy in a private setting sample. Arch Womens Ment Health. 2007; 10(1):25-32. https://doi.org/10.1007/s00737-006-0164-6.

10. Sawyer A, Ayers S, Smith H. Pre- and postnatal psychological wellbeing in Africa: a systematic review. J Affect Disord. 2010;123(1-3):17-29. https://doi. org/10.1016/j.jad.2009.06.027.

11. Jeong HG, Lim JS, Lee MS, Kim SH, Jung IK, Joe SH. The association of psychosocial factors and obstetric history with depression in pregnant women: focus on the role of emotional support. Gen Hosp Psychiatry. 2013; 35(4):354-8. https://doi.org/10.1016/j.genhosppsych.2013.02.009.

12. Chang HY, Keyes KM, Lee KS, Choi IA, Kim SJ, Kim KW, et al. Prenatal maternal depression is associated with low birth weight through shorter gestational age in term infants in Korea. Early Hum Dev. 2014;90(1):15-20. https://doi.org/10.1016/j.earlhumdev.2013.11.006.

13. Bussières EL, Tarabulsy GM, Pearson J, Tessier R, Forest JC, Giquère $Y$. Maternal prenatal stress and infant birth weight and gestational age: a meta-analysis of prospective studies. Dev Rev. 2015;36:179-99. https://doi. org/10.1016/j.dr.2015.04.001.

14. Evans J, Heron J, Patel RR, Wiles N. Depressive symptoms during pregnancy and low birth weight at term. Br J Psychiatry. 2007;191(1):84-5. https://doi. org/10.1192/bjp.bp.105.016568.

15. Nasreen HE, Kabir ZN, Forsell Y, Edhborg M. Low birth weight in offspring of women with depressive and anxiety symptoms during pregnancy: results from a population based study in Bangladesh. BMC Public Health. 2010; 10(1):515. https://doi.org/10.1186/1471-2458-10-515.

16. Rahman A, Bunn J, Lovel H, Creed F. Association between antenatal depression and low birthweight in a developing country. Acta Psychiatr Scand. 2007;115(6):481-6. https://doi.org/10.1111/j.1600-0447.2006.00950.x.

17. Grote NK, Bridge JA, Gavin AR, Melville JL, lyengar S, Katon WJ. A metaanalysis of depression during pregnancy and the risk of preterm birth, low birth weight, and intrauterine growth restriction. Arch Gen Psychiatry. 2010; 67(10):1012-24. https://doi.org/10.1001/archgenpsychiatry.2010.111.

18. Saeed A, Raana T, Saeed AM, Humayun A. Effect of antenatal depression on maternal dietary intake and neonatal outcome: a prospective cohort. Nutr J. 2016;15(1):64. https://doi.org/10.1186/s12937-016-0184-7.

19. Diego MA, Field T, Hernandez-Reif M, Schanberg S, Kuhn C, GonzalezQuintero VH. Prenatal depression restricts fetal growth. Early Hum Dev. 2009;85(1):65-70. https://doi.org/10.1016/j.earlhumdev.2008.07.002

20. Lee DTS, Chung TKH. Postnatal depression: an update. Best Pract Res Clin Obstet Gynaecol. 2007;21 (2):183-91. https://doi.org/10.1016/j.bpobgyn.2 006.10.003.

21. Chapman SLC, Wu L-T. Postpartum substance use and depressive symptoms: a review. Women Health. 2013;53(5):479-503. https://doi.org/10.1 080/03630242.2013.804025

22. Feldman R, Granat A, Pariente C, Kanety H, Kuint J, Gilboa-Schechtman E. Maternal depression and anxiety across the postpartum year and infant social engagement, fear regulation, and stress reactivity. J Am Acad Child Adolesc Psychiatry. 2009;48(9):919-27. https://doi.org/10.1097/CHI.0b013e31 $81 \mathrm{~b} 21651$

23. Lemola S, Stadlmayr W, Grob A. Infant irritability: the impact of fetal alcohol exposure, maternal depressive symptoms, and low emotional support from the husband. Infant Ment Health J. 2009;30(1):57-81. https://doi.org/10.1 002/imhj.20203.

24. McManus BM, Poehlmann J. Parent-child interaction, maternal depressive symptoms and preterm infant cognitive function. Infant Behav Dev. 2012; 35(3):489-98. https://doi.org/10.1016/j.infbeh.2012.04.005.
25. Medhin G, Hanlon C, Dewey M, Alem A, Tesfaye F, Lakew Z, et al. The effect of maternal common mental disorders on infant undernutrition in Butajira, Ethiopia: The P-MaMiE study. BMC Psychiatry. 2010;10(1):32. https://doi.org/1 $0.1186 / 1471-244 X-10-32$

26. Deyessa N, Berhane Y, Emmelin M, Ellsberg M, Kullgren G, Högberg U. Joint effect of maternal depression and intimate partner violence on increased risk of child death in rural Ethiopia. Arch Dis Child. 2010;95(10):771-5. https://doi.org/10.1136/adc.2009.165571.

27. Field T. Prenatal depression effects on early development: a review. Infant Behav Dev. 2011;34(1):1-14. https://doi.org/10.1016/j.infbeh.2010.09.008.

28. Gur C, Diav-Citrin O, Shechtman S, Arnon J, Ornoy A. Pregnancy outcome after first trimester exposure to corticosteroids: a prospective controlled study. Reprod Toxicol. 2004;18(1):93-101. https://doi.org/10.1016/j.reprotox.2 003.10.007.

29. Paykel E. Depression and appetite. J Psychosom Res. 1977;21(5):401-7. https://doi.org/10.1016/0022-3999(77)90049-6.

30. Liberati A, Altman DG, Tetzlaff J, Mulrow C, Gotzsche PC, loannidis JP, et al. The PRISMA statement for reporting systematic reviews and meta-analyses of studies that evaluate healthcare interventions: explanation and elaboration. BMJ. 2009;339:b2700. https://doi.org/10.1136/bmj.b2700.

31. Stang A. Critical evaluation of the Newcastle-Ottawa scale for the assessment of the quality of nonrandomized studies in meta-analyses. Eur J Epidemiol. 2010;25(9):603-5. https://doi.org/10.1007/s10654-010-9491-z.

32. Bae J-M. A suggestion for quality assessment in systematic reviews of observational studies in nutritional epidemiology. Epidemiol Health. 2016;38: e2016014. https://doi.org/10.4178/epih.e2016014.

33. Egger M, Davey Smith G, Schneider M, Minder C. Bias in meta-analysis detected by a simple, graphical test. BMJ. 1997;315(7109):629-34. https:// doi.org/10.1136/bmj.315.7109.629.

34. Duval S, Tweedie R. Trim and fill: a simple funnel-plot-based method of testing and adjusting for publication bias in meta-analysis. Biometrics. 2000; 56(2):455-63. https://doi.org/10.1111/j.0006-341X.2000.00455.x.

35. Higgins JPT, Thompson SG, Deeks JJ, Altman DG. Measuring inconsistency in meta-analyses. BMJ: Br Med J. 2003;327(7414):557-60. https://doi.org/1 0.1136/bmj.327.7414.557.

36. Fletcher J. What is heterogeneity and is it important? BMJ: Br Med J. 2007; 334(7584):94-6. https://doi.org/10.1136/bmj.39057.406644.68.

37. Schmidheiny K. A short guide to Stata 14. Kurt. schmidheiny. name/ teaching/stataguide. pdf. 2016.

38. Wado YD, Afework MF, Hindin MJ. Effects of maternal pregnancy intention, depressive symptoms and social support on risk of low birth weight: A prospective study from Southwestern Ethiopia. PLoS One. 2014;9(5):e96304.

39. Bindt C, Guo N, Bonle MT, Appiah-Poku J, Hinz R, Barthel D, et al. No association between antenatal common mental disorders in low-obstetric risk women and adverse birth outcomes in their offspring: results from the CDS study in Ghana and cote D'Ivoire. PLoS One. 2013;8(11):e80711. https:// doi.org/10.1371/journal.pone.0080711.

40. Guo N, Bindt C, Te Bonle M, Appiah-Poku J, Hinz R, Barthel D, et al. Association of antepartum and postpartum depression in Ghanaian and Ivorian women with febrile illness in their offspring: a prospective birth cohort study. Am J Epidemiol. 2013;178(9):1394-402. https://doi.org/10.1 093/aje/kwt142.

41. Weobong B, Ten Asbroek AHA, Soremekun S, Gram L, Amenga-Etego SD, Danso $S$, et al. Association between probable postnatal depression and increased infant mortality and morbidity: Findings from the DON population-based cohort study in rural Ghana. BMJ Open. 2015;5(8):e006509.

42. Wemakor A, Mensah KA. Association between maternal depression and child stunting in Northern Ghana: A cross-sectional study. BMC Public Health. 2016;16(1):869.

43. Wemakor A, Iddrisu H. Maternal depression does not affect complementary feeding indicators or stunting status of young children (6-23 months) in northern Ghana. BMC Res Notes. 2018;11(1):408. https://doi.org/10.1186/ s13104-018-3528-x.

44. Madeghe BA, Kimani VN, Vander Stoep A, Nicodimos S, Kumar M. Postpartum depression and infant feeding practices in a low income urban settlement in Nairobi-Kenya. BMC Res Notes. 2016;9(1):506.

45. Ashaba S, Rukundo GZ, Beinempaka F, Ntaro M, Leblanc JC. Maternal depression and malnutrition in children in southwest Uganda: A case control study. BMC Public Health. 2015;15(1):1303. 
46. Neamah HH, Sudfeld C, McCoy DC, Fink G, Fawzi WW, Masanja H, et al. Intimate Partner Violence, Depression, and Child Growth and Development. Pediatrics. 2018;142(1):e20173457.

47. Adewuya $\mathrm{AO}$, Ola BO, Aloba OO, Mapayi BM, Okeniyi JA. Impact of postnatal depression on infants' growth in Nigeria. J Affect Disord. 2008; 108(1-2):191-3.

48. Ndokera R, MacArthur C. The relationship between maternal depression and adverse infant health outcomes in Zambia: a cross-sectional feasibility study. Child Care Health Dev. 2011;37(1):74-81. https://doi.org/10.1111/j.13 65-2214.2010.01129.x.

49. Wachs TD, Black MM, Engle PL. Maternal depression: a global threat to Children's health, development, and behavior and to human rights. Child Dev Perspect. 2009;3(1):51-9. https://doi.org/10.1111/j.1750-8606.2008.00077x.

50. Li J, Mao J, Du Y, Morris JL, Gong G, Xiong X. Health-related quality of life among pregnant women with and without depression in Hubei, China. Matern Child Health J. 2012;16(7):1355-63. https://doi.org/10.1007/s10995011-0900-z.

51. Accortt EE, Cheadle ACD, Dunkel Schetter C. Prenatal depression and adverse birth outcomes: an updated systematic review. Matern Child Health J. 2015;19(6):1306-37. https://doi.org/10.1007/s10995-014-1637-2.

52. Alder J, Fink N, Bitzer J, Hösli I, Holzgreve W. Depression and anxiety during pregnancy: a risk factor for obstetric, fetal and neonatal outcome? A critical review of the literature. J Matern Fetal Neonatal Med. 2007;20(3):189-209. https://doi.org/10.1080/14767050701209560.

53. Grigoriadis S, VonderPorten EH, Mamisashvili L, Tomlinson G, Dennis CL, Koren $\mathrm{G}$, et al. The impact of maternal depression during pregnancy on perinatal outcomes: a systematic review and meta-analysis. J Clin Psychiatry. 2013;74(4):e321-e41. https://doi.org/10.4088/JCP.12r07968.

54. Staneva A, Bogossian F, Pritchard M, Wittkowski A. The effects of maternal depression, anxiety, and perceived stress during pregnancy on preterm birth: a systematic review. Women Birth. 2015;28(3):179-93. https://doi.org/1 0.1016/j.wombi.2015.02.003

55. Stewart RC. Maternal depression and infant growth - a review of recent evidence. Matern Child Nutr. 2007;3(2):94-107. https://doi.org/10.1111/j.174 0-8709.2007.00088.x.

56. Surkan PJ, Kennedy CE, Hurley KM, Black MM. Maternal depression and early childhood growth in developing countries: systematic review and metaanalysis. Bull World Health Organ. 2011;89(8):607-15. https://doi.org/10.24 71/BLT.11.088187.

57. de Jager E, Skouteris H, Broadbent J, Amir L, Mellor K. Psychosocial correlates of exclusive breastfeeding: a systematic review. Midwifery. 2013; 29(5):506-18. https://doi.org/10.1016/j.midw.2012.04.009.

58. Dennis C-L, McQueen K. The relationship between infant-feeding outcomes and postpartum depression: a qualitative systematic review. Pediatrics. 2009; 123(4):e736-51. https://doi.org/10.1542/peds.2008-1629.

59. Surkan PJ, Kawachi I, Ryan LM, Berkman LF, Vieira LMC, Peterson KE. Maternal depressive symptoms, parenting self-efficacy, and child growth. Am J Public Health. 2008;98(1):125-32. https://doi.org/10.2105/AJPH.2006.1 08332.

60. Waqas A, Elhady M, Surya Dila KA, Kaboub F, Van Trinh L, Nhien CH, et al. Association between maternal depression and risk of infant diarrhea: a systematic review and meta-analysis. Public Health (Elsevier). 2018;159:7888. https://doi.org/10.1016/j.puhe.2018.01.036.

61. Teychenne M, York R. Physical activity, sedentary behavior, and postnatal depressive symptoms: a review. Am J Prev Med. 2013;45(2):217-27. https:// doi.org/10.1016/j.amepre.2013.04.004

62. Pearson RM, Melotti R, Heron J, Joinson C, Stein A, Ramchandani PG, et al. Disruption to the development of maternal responsiveness? The impact of prenatal depression on mother-infant interactions. Infant Behav Dev. 2012; 35(4):613-26.

63. Wichman CL, Stern TA. Diagnosing and Treating Depression During Pregnancy. Prim Care Companion CNS Disord. 2015;17(2).

\section{Publisher's Note}

Springer Nature remains neutral with regard to jurisdictional claims in published maps and institutional affiliations.

\section{Ready to submit your research? Choose BMC and benefit from:}

- fast, convenient online submission

- thorough peer review by experienced researchers in your field

- rapid publication on acceptance

- support for research data, including large and complex data types

- gold Open Access which fosters wider collaboration and increased citations

- maximum visibility for your research: over $100 \mathrm{M}$ website views per year

At BMC, research is always in progress.

Learn more biomedcentral.com/submissions 